\title{
The Dynamics of Environmental and Economic Systems - Innovation, Environmental Policy and Competitiveness \\ Valeria Costantini, Massimiliano Mazzanti (Eds.)
}

Londres: Springer, 231 p., 2013.

\section{Thomaz Teodorovicz*}

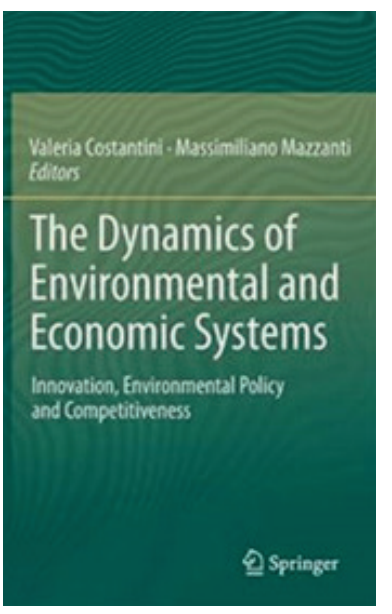

The dynamics of environmental and economic systems é uma coletânea de textos, cujo fio condutor é a tentativa de estabelecer um diálogo entre as abordagens neoclássica e evolucionária, no que tange à análise de inovações voltadas para proteção ambiental. Essa é, justamente, a área de trabalho dos editores do livro. Professora associada do Departamento de Economia da Università degli Studi Roma Tre, Valeria Costantini estuda as áreas de economia ambiental, políticas ambientais e intersecção entre inovação e meio ambiente. Massimiliano Mazzanti é professor de Economia na Università di Ferrara, alocado no Departamento de Instituições Econômicas e Território. Seus trabalhos englobam economia ambiental e suas relações com políticas públicas, inovações tecnológicas e gerenciamento de recursos naturais.

A motivação dos editores decorre de duas lacunas nos estudos sobre impactos econômicos e eficácia de políticas ambientais. A primeira diz respeito às análises neoclássicas, pautadas exclusivamente em pressupostos estáticos de falhas de mercado, que obscurecem a inovação como propulsor de sustentabilidade e competitividade. Em segundo lugar, eles ressaltam a escassez de análises empíricas de políticas

* Mestrando do Programa de Pós-Graduação em Políticas Públicas, Universidade Federal do Paraná (UFPR), Curitiba (PR), Brasil. E-mail: teo.thomaz@gmail.com 
ambientais e a desconsideração, nos modelos aplicados, de especificidades técnicas setoriais. Assim, esta coletânea busca valorizar a inovação tecnológica e conceitos da economia evolucionária, incorporando-os à relação entre economia e meio ambiente.

Para tanto, a coletânea fundamenta-se na articulação de quatro aspectos teórico-metodológicos fundamentais: modelos híbridos (econômico-ambientais) aplicados à análise de políticas públicas; centralidade da dinâmica, resultante do processo inovador, na evolução de sistemas econômico-ambientais; inovação tecnológica como causa e efeito da agenda ambiental; e importância de trabalhos setoriais em detrimento de estudos agregados. Estabelecer o diálogo entre vertentes neoclássica e evolucionária impõe, todavia, um grande desafio. Enquanto a primeira considera a inovação e o meio ambiente como variáveis exógenas à economia, restringindo-se a análises econométricas de impacto do tipo insumo-produto, a segunda exalta a endogeneidade do processo inovador, promovendo análises qualitativas de mecanismos de feedback, fluxos de informações, redes de atores e instituições.

O livro está organizado em duas partes. A primeira (cap. 1 a 5) enfoca o macroambiente institucional que permeia a relação entre meio ambiente, economia e inovação. Já a segunda (cap. 6 a 11) apresenta estudos de caso que analisam a dinâmica, os determinantes e os impactos de inovaçōes sustentáveis em níveis macro, meso e micro.

Na primeira parte, Antimiani et al. (cap. 1) expõem um modelo híbrido para mensuração de impactos macroeconômicos e ambientais de políticas governamentais. Tal modelo é aplicado por Antimiani et al. (cap. 2) na discussão sobre tarifas comerciais de carbono. Mantendo uma análise estática de otimização, os resultados indicam ineficiência desse mecanismo como política ambiental. A maior contribuição foi, todavia, a adoção de fronteiras de substituição energética, entre combustíveis fósseis e fontes renováveis, refletindo especificidades técnicas setoriais. As "macroinstituiçōes" do processo inovador são consideradas por Abadie et al. (cap. 4) e Wagner (cap. 5). Os primeiros analisam os Industrial Assessment Centers (IACs), centros públicos para desenvolvimento e disseminação de inovaçôes energéticas sustentáveis às pequenas e médias empresas, nos EUA. Os autores verificam que empresas são mais suscetíveis à adoção das inovações recomendadas pelos IACs quanto menores forem o payback e o montante de investimento inicial e quanto maior for o benefício financeiro esperado. Entretanto, custos apresentam maior influência do que benefícios. Assim, a aversão a custos no curto prazo limita a adoção voluntária de tecnologias sustentáveis mesmo quando há benefícios líquidos futuros. Wagner explora a influência de regulações ambientais na adoção de inovaçôes e na competitividade das firmas. Entrevistas 
e questionários respondidos por 169 empresas do setor manufatureiro na Alemanha alimentaram um modelo estatístico de determinantes de inovação ambiental. Apesar de identificar uma correlação positiva entre regulação ambiental e atividade inovadora, o autor encontra diversos fatores institucionais e econômicos (histórico de sustentabilidade das firmas, preferência dos stakeholders por açôes sustentáveis vis-à-vis lucros privados e potencial abertura de novos mercados) complementares à promoção de inovações sustentáveis e ganhos competitivos.

A partir do cap. 6, estudos de caso aplicam ferramentas empíricas para analisar a relação entre inovação e sustentabilidade, expondo a influência de diferentes características políticas, setoriais e privadas. Kalamova et al. (cap. 6) reportam, a partir de dados de 23 países da OCDE (1986-2006), o efeito negativo da incerteza política relativa à agenda ambiental, representada pela oscilação de recursos públicos destinados à $\mathrm{P} \& \mathrm{D}$ no segmento ambiental. Evidenciou-se que flutuações de $10 \%$ na incerteza política geram reduções de até $2,8 \%$ na submissão de novas patentes de tecnologias sustentáveis. Determinantes microeconômicos de inovações sustentáveis são explorados por Oehme e Kemp (cap. 7), que confirmam que a performance ambiental de uma empresa é mais relacionada à sua posição perante outros valores sociais do que à sua propensão a inovar. Se Nicolli (cap. 8) aborda a influência de políticas ambientais e energéticas nas emissões de poluentes em diversos setores industriais de oito países europeus, Crespi (cap. 10) evidencia o papel do rigor de regulações ambientais no número de patentes no segmento de tratamento de resíduos em 28 países da OCDE (1980-2008). O primeiro identifica uma relação positiva entre o alcance dos objetivos delimitados pelo Protocolo de Kyoto e inovaçóes tecnológicas, enquanto o segundo verifica um impacto inovador positivo, mas inconstante, do rigor regulatório. Marin (cap. 9) estuda a difusão internacional de inovaçôes sustentáveis em 23 setores produtivos de 13 países da OCDE (1996-2007). A difusão tecnológica mostrou-se mais intensa quanto maior for o diferencial de eficiência na utilização de recursos energéticos entre países "atrasados" e "líderes", ilustrando uma complementaridade entre sustentabilidade e produtividade. Finalmente, Constantini et al. (cap. 11) propõem uma metodologia para definição de patentes em nível setorial. A partir de entrevistas com especialistas, são elencadas técnicas e palavras-chave "relevantes" para um setor específico, utilizadas como filtro na busca de patentes.

Não obstante os resultados apresentados, o objetivo de mesclar análises neoclássica e evolucionária não foi efetivamente atendido. Se variáveis como difusão tecnológica, spill-overs, influência regulatória, estabilidade política e características setoriais foram incorporadas aos estudos, as metodologias basearam-se na mensu- 
ração de efeitos isolados dos determinantes da inovação e de impactos econômico-ambientais. A discussão das relaçôes entre economia, inovação e meio ambiente ficou restrita à perspectiva neoclássica de insumo-produto. Ao enfatizar uma análise essencialmente quantitativa, os textos desconsideram importantes fatores qualitativos associados a fluxos de conhecimento, conexões entre firmas e agentes públicos com valores éticos e de preservação da natureza que vão além do valor econômico atribuído aos recursos ambientais. Uma exceção deve ser feita ao texto de Del Río e Bleda (cap. 3). Nele, os autores enfatizam a necessidade da análise dos processos de aprendizagem e das redes de atores e instituições que compõem sistemas setoriais de inovação.

O principal mérito do livro de Costantini e Mazzanti é chamar a atenção para a necessidade de políticas ambientais não somente repressivas ou technology-enforcers, mas que também estimulem inovações sustentáveis capazes de conciliar objetivos econômicos e ambientais. Neste caso, uma perspectiva sistêmica, que considere a interdependência dos atores, seus fluxos de informação e os determinantes qualitativos imersos na relação entre inovação, meio ambiente e economia, permanece um campo a ser explorado. Mas isto ocorreria em detrimento do enfoque neoclássico e de um ferramental econométrico limitado na possibilidade de incorporar a complexidade dos mecanismos sistêmicos associados à inovação. Ao mesmo tempo, a incorporação das variáveis institucionais na análise do processo de inovação ambiental ainda impõe um desafio teórico-metodológico à abordagem evolucionária, apesar de muitos autores reconhecerem sua importância. 
A Revista Brasileira de Inovação está aberta à comunidade científica para divulgação de artigos originais e inéditos, de natureza teórica ou aplicada, resultados de pesquisas, bem como trabalhos que contribuam para o resgate da história das instituições brasileiras no campo da ciência, da tecnologia e da inovação.

São aceitas submissões de artigos com no máximo 8.000 palavras e resenhas de até 1.000 palavras, inéditos em português, inglês ou espanhol.

Todos os trabalhos devem ser submetidos via Sistema Eletrônico de Editoração de Revistas (SEER) e se enquadrar na linha editorial da revista, observando as normas e orientações indicadas a seguir:

- os trabalhos devem ser redigidos conforme a norma de apresentação de artigos da Associação Brasileira de Normas Técnicas - ABNT (NBR6022) ou norma ISO equivalente, digitados no editor de texto Word 6.0 (extensão doc. ou docx.), texto na fonte Times New Roman 12; configuração de página A4; margens direita, superior e inferior com 2,5cm; margem esquerda com 3cm; espaçamento entrelinhas de 1,5; recuo de 1,25 na primeira linha; alinhamento do texto justificado; e numeração de páginas no canto superior direito;

- $\quad$ os artigos devem ser submetidos contendo resumo, título e palavras-chave em seu idioma original e em inglês e classificação segundo o Classification System for Journal Articles do Journal Economic Literature. O resumo/abstract deve ter no máximo 150 palavras e possuir de três a cinco palavras-chave;

- as resenhas devem versar sobre livros publicados nos últimos três anos, relacionados à inovação e que estejam alinhados ao escopo editorial da revista;

- as obras citadas no corpo do texto e em notas de rodapé (autor, ano da publicação e, quando for o caso, página) deverão estar completas nas referências bibliográficas ao final do texto.

Os artigos são avaliados no sistema blind review por três pareceristas de instituições distintas daquela à qual o(s) autor(es) está(ão) vinculado(s) e as resenhas são avaliadas pelos editores da revista.

Os direitos autorais dos trabalhos aprovados são automaticamente transferidos à $R B I$ como condição para sua publicação, podendo ser compartilhados desde que com o reconhecimento de sua autoria e publicação inicial nesta revista.

Mais informações: <http://www.ige.unicamp.br/ojs/index.php/rbi/>> 
